\title{
A TEORIA GEOSSISTÊMICA NA PESQUISA GEOMORFOLÓGICA: UMA ABORDAGEM TEÓRICO-CONCEITUAL
}

\author{
THE GEOSYSTEMIC THEORY IN \\ GEOMORPHOLOGICAL RESEARCH: \\ A THEORETICAL-CONCEPTUAL APPROACH
}

\author{
Caio Lima-dos Santos ${ }^{1}$ \\ Osvaldo Girão ${ }^{2}$ \\ Universidade Federal de Pernambuco, Brasil.
}

\begin{abstract}
RESUMO
A teoria geossistêmica está fortemente inserida na geográfica física, sobretudo no campo da pesquisa geomorfológica. Essa teoria busca realizar suas analises através da relação de causa e efeitos dos elementos que compõe o sistema terrestre, bem como tenta explicar como esses elementos se materializam no tempo e no espaço. Este artigo tem por objetivo realizar uma discussão teórica e conceitual sobre a teoria geossistêmica e seu desenvolvimento dentro da pesquisa geomorfológica, fazendo assim uma reflexão sobre o potencial e as fragilidades apresentadas por essa teoria. Destaca-se, portanto, a importância dessa teoria para orientar a ocupação territorial, considerando os atributos físico-ambientais e sua dinâmica, com intuito estabelecer uma ação humana menos onerosa à natureza e a sociedade que faz uso desses espaços.
\end{abstract}

Palavras chave: abordagem sistêmica, aplicações, geografia física

\footnotetext{
1 Mestrando do Programa de Pós-graduação em Geografia da Universidade Federal de Pernambuco - Brasil. Email: caiolima21@hotmail.com

2 Professor de Geografia da Universidade Federal de Pernambuco - Brasil. Email: osgirao@gmail.com
} 
Caio Lima-dos Santos, Osvaldo Girão. The Geosystemic Theory in geomorphological research:

a theoretical-conceptual approach

\begin{abstract}
The geosystemic theory is strongly embedded in Physical Geography, especially in the field of geomorphological research. This theory seeks to accomplish its analysis through the cause-effect relation of the elements that compose the Earth system, and it also attempts to explain how these elements are materialized in time and space. This article aims at making a theoretical and conceptual discussion on geosystemic theory and its development within the geomorphological research, thus making a reflection on the potential and weaknesses presented by this theory. We emphasize; however, the importance of this theory to guide land occupation considering the physical and environmental attributes and its dynamics in order to establish a less onerous nature and human society action that use these spaces.
\end{abstract}

Keywords: systemic approach, application, physical geography

\title{
RESUMEN
}

La teoría geosistémica está fuertemente inserida en la geografía física, principalmente, en el campo de la pesquisa geomorfológica. Esa teoría busca realizar sus análisis a través de la relación de causa y efecto de los elementos que componen lo sistema terrestre, así como intenta explicar cómo esos elementos se materializan en el tiempo y en el espacio. Este artículo, tiene como objetivo realizar una discusión teórica y conceptual sobre la teoría geosistémica y su desenvolvimiento dentro de la pesquisa geomorfológica, haciendo así una reflexión sobre el potencial y las fragilidades presentadas por esa teoría. Destacase, de tal modo, la importancia de esa teoría para orientar la ocupación territorial considerando los atributos físicos ambientales y su dinámica, con el intuito de establecer una acción humana menos onerosa para la naturaleza y la sociedad que utiliza esos espacios.

Palabras clave: Abordaje sistémica; aplicaciones; geografía física.

\section{Introdução}

A ocupação indiscriminada da superfície terrestre tem se refletido em diversos problemas de ordem ambiental, principalmente na formação de situações de riscos geomorfológicos, tanto em áreas consideradas urbanas quanto rurais, pois a utilização desordenada do espaço e dos recursos naturais gera desequilíbrios aos sistemas ambientais físico/naturais, situações estas que, eventualmente, podem atingir diretamente o cotidiano de indivíduos ou grupos sociais.

A produção científica em torno dos problemas relacionados aos riscos considerados geomorfológicos, relativos aos eventos naturais derivados de processos endógenos exógenos, apresenta certo grau de desenvolvimento em fins do século passado, tendo em vista os avanços para compreensão da dinâmica de diversos processos geomorfológicos, mas também o reconhecimento do papel da ocupação de espaços propensos à ocorrência de determinados eventos naturais, aspectos estes que passam a embasar a possibilidade de reconhecimento do grau de susceptibilidade 
que um determinado grupo social pode apresentar conforme se realiza a ocupação de uma determinada porção da superfície terrestre.

Assim, a adoção de uma metodologia que agregue os elementos bióticos (biológicos), abióticos (físicos) e humanos (econômicos, sociais e tecnológicos) em uma mesma perspectiva de análise, que agregue aspectos quantitativos e qualitativos, além de localizá-los espacialmente, para poder assim tentar compreender como se realiza a relação dinâmica e caótica que se estabelece entre esses elementos, surge como base teórica-conceitual e mesmo metodológica para tais fins.

Desta forma, a teoria geossistêmica vem embasando inúmeras pesquisas no campo da geomorfologia nas duas últimas décadas, pois esta apresenta um importante arcabouço teórico-metodologico capaz de orientar a ocupação da superfície terrestre de modo que seja possível minimizar o desequilíbrio da dinâmica natural causados pela ação ocupacional humana, mesmo reconhecendo que ainda existam alguns aspectos nesta teoria que necessitem ser revisto e reformulados, o que não implica, porém em depreciação de sua relevância.

A teoria geossistêmica é campo de analise para a Geografia, que aborda os elementos que compõe a dinâmica natural de uma determinada porção do espaço numa visão holística, tentando compreender como se realizada a relação entre elementos naturais e humanos.

O presente artigo tem por objetivo realizar uma discussão teórica e conceitual sobre a teoria geossistêmica e seu desenvolvimento dentro da pesquisa geomorfológica, fazendo assim uma reflexão sobre as potencialidades e as fragilidades apresentadas por essa teoria. Desse modo, foi realizada uma revisão da literatura que fundamenta esse campo de análise e de pesquisas geomorfológicas fundamentadas nesse conceito, destacando a visão dos autores, para assim obter um quadro geral sobre o desenvolvimento da pesquisa neste campo de estudos.

\section{A teoria geossistêmica}

$\mathrm{Na}$ atualidade as pesquisas no campo da geomorfologia estão fortemente orientadas pelo viés geossistêmico, observando que os diversos elementos que atuam na formação do relevo interagem entre si em uma dinâmica não linear e caótica. Sendo assim, faz-se necessário compreender como se realiza essa dinâmica e a constante troca de energia e matéria entre estes elementos. 
Caio Lima-dos Santos, Osvaldo Girão. The Geosystemic Theory in geomorphological research: a theoretical-conceptual approach

A teoria geossistêmica foi inicialmente proposta pelo geógrafo e geobotânico Viktor Borisovich Sotchava em um estudo pioneiro em 1960, estando suas raízes fincadas na Teoria Geral dos Sistemas (TGS) (Bertalanffy, 1973). Segundo a concepção apresentada na TGS, é de fundamental importância estudar o objeto considerando a relação dinâmica existente entre os elementos que o compõe, pois o comportamento das partes se mostra diferentes quando estudados separadamente. Essa necessidade se apresenta mediante a ineficácia teórico-metodológica da ciência clássica para apresentar soluções práticas aos problemas socioambientais, tendo em vista sua abordagem mecanicista e isolada das series causais (Bertalanffy, 1973 apud Marques Neto, 2008, p.70).

Conforme atesta Rodrigues (2001), a TGS persiste como ideia percursora de uma série de referências relevantes para os estudos da Geografia Física, pois a mesma remonta a fase que se inicia a valorização da mensuração/quantificação e a incorporação definitiva da dimensão temporal aos estudos geográficos, quando se adotam as modelagens e ampliamse as experimentações.

Constituindo-se em um marco inicial relativo a um emergente paradigma para os estudos do meio físico que seria o método baseado nos Geossistemas, o artigo Paisagem e Geografia Física Global do professor George Bertrand, publicado em 1968 na França, constituiu-se no primeiro artigo a influenciar sobre os geógrafos brasileiros, já no ano de 1969, por se constituir na primeira revelação do conceito de Geossistema para a comunidade dos geógrafos do Brasil (Monteiro, 2000; Girão, 2007).

Como um geógrafo dedicado aos estudos biogeográficos, Bertrand apresentou uma proposta especificamente "geográfica", sem pretensões de ser confundida com as propostas da biologia relativas aos Ecossistemas, tendo como elementos básicos integrantes o potencial ecológico, exploração biológica e a ação antrópica, sua proposta possuía uma dinâmica funcional regida por um sistema geomorfológico, pela dinâmica biológica e pela exploração antrópica. Contudo, apesar do artigo de Bertrand, que representou o primeiro texto que fez referência ao conceito de Geossistema a chegar ao Brasil, foi em estudos desenvolvidos no âmbito das ciências naturais durante as décadas de 1960 e 1970 na Europa Central e na antiga União das Repúblicas Socialistas Soviéticas (URSS), que esse método de estudo adotado pela Geografia Física teve sua origem, baseado nos princípios sistêmicos e na noção de paisagem (Girão, 2007). 
A temática geossistêmica, no Leste europeu, e especificamente na URSS, chega-nos através do professor Carlos Augusto de Figueiredo Monteiro, quando de sua participação no Congresso Internacional de Geografia da União Geográfica Internacional (UGI) na cidade de Moscou, em 1976. Durante tal evento o professor Monteiro participou de uma excursão a Sibéria, onde na cidade Novosibirsk mantém contato com o professor Sotchava, geógrafo do Instituto de Geografia da Sibéria e Extremo Oriente, e coordenador de uma equipe empenhada no Estudo de Geossistemas (Monteiro, 2000; Girão, 2007). Quando desse contato, o professor Sotchava oferece, a título de intercâmbio acadêmico, uma publicação, apresentada em inglês para o Congresso da UGI, intitulada "O Estudo de Geossitemas" que, a partir da solicitação e autorização do professor Sotchava para tradução, feita pelo professor Monteiro, é publicada como artigo pelo Instituto de Geografia da Universidade de São Paulo.

Sotchava (1977) apresenta o geossistema como sendo um sistema natural, onde os elementos naturais interagem entre si formando uma dinâmica harmônica entre ação e resultado, porém, o autor destaca que atuação humana não deve ser descartada nessa dinâmica, sendo avaliada conjuntamente com os aspectos que caracterizam os elementos naturais.

Ademais, ainda segundo Sotchava (1977 apud Mendonça, 1989, p.49), o Geossistema constitui-se na "expressão dos fenômenos naturais, ou seja, o potencial ecológico de determinado espaço no qual há uma exploração biológica, podendo influir fatores sociais e econômicos na estrutura e expressão espacial, porém, sem haver necessariamente, face aos processos dinâmicos, uma homogeneidade interna". O Geossistema resulta da interação de fatores geomorfológicos, climáticos, hidrológicos e fitogeográficos, sendo esse último fator, na concepção de Sotchava, de grande relevância na identificação das unidades de paisagem (Girão, 2007).

A concepção geossistêmica de Sotchava constitui-se em uma tentativa de inter-relacionar e aprofundar os estudos realizados pela Geografia Física, sendo que a modelização dos Geossistemas a partir de sua dinâmica espontânea antropogênica e do regime natural objetiva a efetivação de uma maior integração entre os estudos do meio natural e do meio social. Para Monteiro (2000), outro mérito em "O Estudo de Geossitemas" foi à distinção entre os conceitos de "ecossistema" e "geossistema", retomado por Christofoletti (1997), para quem os Geossistemas possuem uma expressão 
Caio Lima-dos Santos, Osvaldo Girão. The Geosystemic Theory in geomorphological research:

a theoretical-conceptual approach

espacial na superfície, dinamizada pela interação areal dos fluxos de matéria e energia entre os componentes que o compõe, sejam eles vivos ou abióticos. Assim, os Geossistemas constituem-se em uma organização espacial mais abrangente e complexa, que contém Ecossistemas locais, aqui compreendidos como uma unidade composta por organismos interagindo com o meio ambiente físico permutando materiais entre seus componentes a partir de fluxo de energia (Christofoletti, 1997; Girão, 2007).

Para Christofoletti (1999) a abordagem holística sistêmica é o caminho para compreender como os elementos físico-ambientais se estruturam e funcionam em sua organização espacial. Ainda segundo Christofoletti (1999), a abordagem reducionista não contrapõe a abordagem holística, tornando-se assim necessária para se obter a caracterização individualizada dos elementos que compõe o sistema, para posteriormente analisar sua relação no conjunto com outros elementos que o forma.

Nessa abordagem, o mundo é visto como um sistema orgânico, onde o conjunto de elementos não é tão somente o resultado da somatória das partes que o compõe, mas se estabelece numa hierarquização de elementos e processos, que formam assim uma dinâmica, alcançando, portanto, o estado de equilíbrio dinâmico. Esse estado só será alterado quando houver a introdução de um elemento capaz de modificar a dinâmica, forçando o sistema a absorver o impacto e reajustar o estado de equilíbrio, conforme relata Christofoletti (1999, p. 2): "Nessa perspectiva, os grupos humanos devem compreender as características e o funcionamento dos sistemas do meio ambiente e evitar a introdução de ações que provoquem rupturas no equilíbrio, ocasionando os impactos ambientais que ultrapassem a estabilidade existente".

Conforme Christofoletti (1999), a análise sistêmica não deve considerar tão somente os elementos físico-naturais (geologia, relevo, clima, vegetação, solo, etc.), mas também as informações sobre as atividades socioeconômicas e a forma que ocorre o uso e ocupação da terra. Estes aspectos devem ser analisados em conjunto para que seja possível compreender a ação humana sobre a dinâmica natural, conforme descreve a figura 1 . 
Figura 1. Estruturação do geossistema e do sistema socioeconômico

GEOSSISTEMA

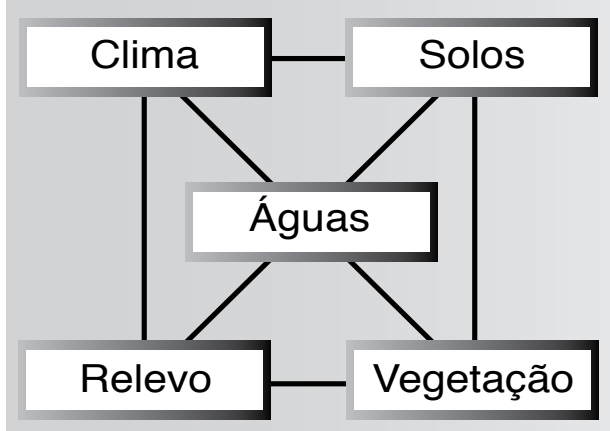

SISTEMA SÓCIO-ECONÔMICO

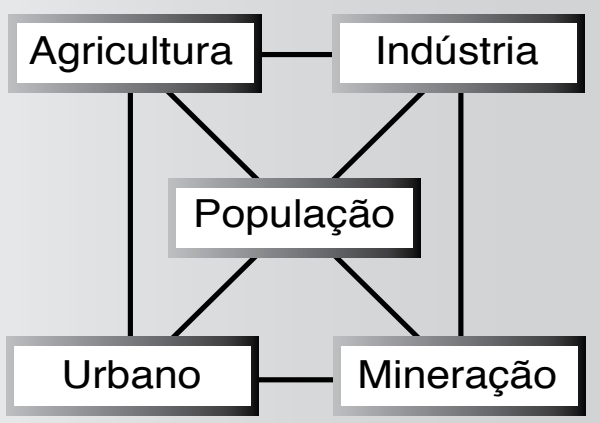

Fonte: Christofoletti (1999, p.41).

Para Monteiro (2000), o aspecto mais promissor e relevante presente na obra de Sotchava foram às técnicas de modelização convergentes que levaram à caracterização dos "regimes" dos geossistemas, fator de importância capital para o reconhecimento da dinâmica processual das unidades geoambientais, enfatizando a relevância do "ritmo" e da "dinâmica temporal" projetada sobre o espaço, tendo como aplicação dos avanços nos estudos do Geossistema como paradigma para os estudos da Geografia Física, realizados por Monteiro, no seu caso com ênfase para os de climatologia, o enriquecimento proporcionado pela representação temporal a ser projetada no espaço em sua representação no plano horizontal (Monteiro, 2000).

A representação temporal presente na dinâmica processual do Geossistema é inserida nos estudos do Professor Monteiro a partir do artigo "Derivações Antropogênicas dos Geossistemas Terrestres no Brasil e Alterações Climáticas: (...)" (Monteiro, 1978), quando, em sua tentativa de modelização visando pesquisas geossistêmicas voltadas à climatologia nas escalas inferiores de organização espacial integradas aos sistemas naturais e incorporando as derivações antrópicas, a temporalidade está presente em painéis verticais objetivando a percepção da dinâmica funcional interna dos elementos móveis que revelam o "regime" ou dinâmica temporal que, em sequências dos elementos ativos, revelam dinâmica processual geossistêmica (Girão, 2007). 
Caio Lima-dos Santos, Osvaldo Girão. The Geosystemic Theory in geomorphological research: a theoretical-conceptual approach

A inserção das sequências temporais nos estudos geossistêmicos foi de grande relevância na avaliação da dinâmica da paisagem, uma vez que se inseriu uma componente não explicita, até os estudos de Monteiro a partir da década de 1970, que eram as variações ou regimes anuais derivados da dinâmica temporal, que influenciavam sobre a dinâmica processual e nas formas presentes nas Unidades Geoambientais componentes de um Geossistema.

Para Bertrand (1971) os estudos geossistêmicos compõe um nível de analise em uma escala necessária para o estudo da paisagem como algo dinâmico, que está em constante processo evolutivo de alteração de seus elementos, afirmando que:

A paisagem não é a simples adição de elementos geográficos disparatados. É, em uma determinada porção do espaço, o resultado da combinação dinâmica, portanto instável, de elementos físicos, biológicos e antrópicos que, reagindo dialeticamente uns sobre os outros, fazem da paisagem um conjunto único e indissociável, em perpétua evolução. (Bertrand, 1971, p. 141).

O autor enfatiza ainda que essa abordagem não contempla tão somente a paisagem dita "natural", mas sim a paisagem total, integrando todas as implicações antrópicas que caracterizam o ambiente.

O referido autor apresenta um sistema de classificação da paisagem, que comporta seis níveis de classificação temporo-espaciais, que são: a zona, o domínio e região como unidades superiores; e o geossistema, a geofácies e o geótopo como unidades de paisagem inferiores. Ele afirma que as pesquisas nesse campo de analise tem se limitado as unidades inferiores, como assim descreve abaixo:

$\mathrm{O}$ geossistema situa-se entre a $4^{\mathrm{a}}$ e a $5^{\mathrm{a}}$ grandeza temporo-espacial. Trata-se, portanto, de uma unidade dimensional compreendida entre alguns quilômetros quadrados e algumas centenas de quilômetros quadrados. É nesta escala que se situa a maior parte dos fenômenos de interferência entre os elementos da paisagem e que evoluem as combinações dialéticas mais interessantes para o geógrafo. Nos níveis superiores a ele só o relevo e o clima importam e, acessoriamente, as grandes massas vegetais. Nos níveis inferiores, os elementos biogeográficos são capazes de mascarar as combinações de conjunto. Enfim, o geossistema constitui uma boa base para os estudos de organização do espaço porque ele é compatível com a escala humana. (Bertrand, 1971, p. 146). 
Na figura 2 temos a ideia teórica de um geossistema, colocando o clima, a hidrologia e a geomorfologia como fatores de primeira ordem na hierarquia sistêmica. A ação desses fatores em conjunto irá determinar os fatores de segunda ordem: a vegetação, o solo e fauna, formando assim o geossistema. A ação antrópica transita nesses dois níveis hierárquicos, atuando como um fator capaz de alterar a dinâmica desse sistema. $\mathrm{O}$ geossistema estará em estado de clímax quando há equilíbrio entre o potencial ecológico e a exploração biológica, porém, isso se torna algo muito improvável, tendo em vista que esses dados sobre a dinâmica desse sistema são muito instáveis, variando tanto em relação ao tempo, quanto em ralação ao espaço.

A evolução conceitual do Geossistema como método de pesquisa prosseguiu ao longo das décadas de 1980 e 1990, e sua utilização transpõem os gabinetes acadêmicos a partir de seu uso para fins de planejamento territorial. Constituindo-se em subdivisões de uma região em áreas que possuam atributos físicos comuns, diferenciados daqueles das áreas circunvizinhas, o Geossistema representa um padrão recorrente de topografia, pedologia e cobertura vegetal, que são reflexos da geologia, processos erosivos e deposicionais e, por conseguinte, do clima onde esses processos ocorrem.

Figura 2. Esboço de uma definição teórica de um geossistema

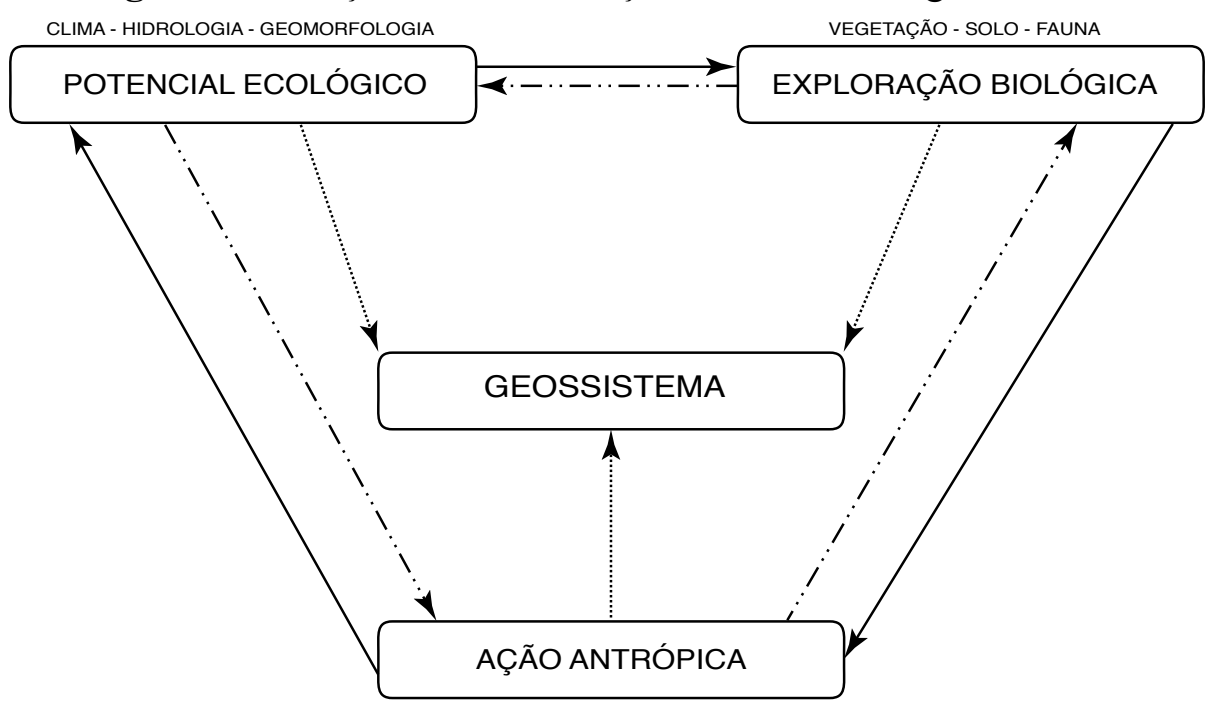

Fonte: Bertrand (2004, p.146). 
Caio Lima-dos Santos, Osvaldo Girão. The Geosystemic Theory in geomorphological research: a theoretical-conceptual approach

Espacialmente, a divisão de um Geossistema por componente de detalhe é a Unidade Ambiental, que se constitui de grande relevância para fins de avaliação de áreas visando empreendimentos agrícolas ou mesmo de engenharia, bem como para o estabelecimento de classificações, objetivando a amenização ou mesmo resolução de problemas de ordem ambiental (Corrêa, 2004; Girão, 2007).

Portanto, torna-se evidente a importância da analise sistêmica nos estudos geomorfológicos, pois esta base teórico-conceitual permite ao pesquisador compreender a forma como se realiza a dinâmica natural entre os elementos que caracterizam uma determinada unidade de paisagem e como se dá sua evolução no tempo e no espaço, para assim poder compreender até que ponto a ação humana será capaz de alterar essa dinâmica.

\section{A teoria geossistêmica na pesquisa geomorfológica}

Atualmente, diversos trabalhos realizados no campo da geomorfologia têm se fundamentado na teoria geossistêmica, tentando responder as necessidades urgentes do mundo moderno em orientar a ocupação da superfície terrestre de modo harmônico e sustentável, tendo vista uma melhor relação da sociedade humana com a natureza.

Na perspectiva geossistêmica, o relevo é visto como um componente, ou elemento, de um sistema complexo, interagindo com os demais elementos que formam a paisagem, em uma ideia de conjunto. Não se pode considerar o relevo como um elemento isolado, ou até mesmo querer compreendê-lo separadamente em relação aos demais elementos do quadro físico/natural.

Compreendendo a paisagem como fisionomia do geossistema, Silva (2008) destaca que a paisagem é a aparência da bioesfera, da litosfera e da hidrosfera vistas de modo integrado.

Rodriguez et. al. (2004) apresentam os fatores geológicos, climáticos, geomorfológicos, hídricos, edáficos e bióticos como fatores geoecológicos formadores da paisagem. Estes fatores, segundo a visão dos autores, são responsáveis pela composição substancial, estrutural, funcional, evolutiva e dinâmica da paisagem. Com base nesta perspectiva, as características do relevo irão resultar da relação estabelecida entre a geologia e o clima atuantes em uma determinada área da superfície terrestre, que condicionam o regime hídrico e atuam como fator preponderante na 
gênese de materiais derivados e mesmo na formação de solos. Essa relação influencia de forma marcante nas condições naturais para a evolução biótica de um sistema.

Ab'Sáber (1969) propunha que a pesquisa geomorfológica fosse compartimentada a partir de níveis de tratamento, considerando primeiramente a compartimentação da topografia regional, constituindo o primeiro nível de análise. Em um segundo momento, deveria se buscar obter informações sistemáticas sobre a estrutura superficial das paisagens referentes a todos os compartimentos e formas de relevo observadas. Este procedimento de analise permitirá obervar formas residuais e recentes que caracterizam o relevo. Em um terceiro momento, a análise geomorfológica deveria observar os processos morfodinâmicos e a pedogênese atual, sendo possível analisar a funcionalidade atual da unidade de paisagem investigada.

A proposta de Ab'Sáber (1969) é de fundamental importância por permitir a análise não só das características atuais do geossistema, mas nos remete a observar como se deu sua evolução no tempo e no espaço a partir de uma modalidade de pesquisa efetivamente dinâmica, sendo assim possível postular sua configuração futura (prognóstico), mediante o seu desenvolvimento natural ou sob a atuação excepcional de um elemento no sistema, seja de ordem natural ou antrópica.

Bertrand (1971) destaca que o primeiro ponto de analise da paisagem está condicionado à ideia de zonalidade, sendo de fundamental importância à compreensão da característica climática predominante nas zonas térmicas da Terra nas quais estão inseridos objetos a serem estudados. A distribuição de radiação solar se dá de modo diferenciado, sendo a zona tropical responsável por receber radiação com maior intensidade, o que refletirá em características próprias de solo, relevo e cobertura vegetal. No interior das zonas climáticas encontra-se o domínio, normalmente marcado, pela espacialização de um determinado aspecto vegetal e/ ou geomorfológico. O domínio amazônico, por exemplo, constitui-se em exemplo para ilustrar esta reflexão, caracterizando-se por estar localizado em latitudes equatoriais, resultando em elevado índice pluviométrico, solo lixiviado e vegetação arbórea densa exuberante, sendo lócus de uma das maiores bacias hidrográficas do planeta. Assim, compreendidas as características zonais, o próximo passo é analisar como esses aspectos se configuram a nível regional, tendo em vista que os processos geológicos 
Caio Lima-dos Santos, Osvaldo Girão. The Geosystemic Theory in geomorphological research:

a theoretical-conceptual approach

em consonância com clima resultam na gênese de diferentes formas resultantes de diferentes processos geomorfológicos.

Compreendendo esses três fatores de macro escalas, tornasse assim possível analisar o geossistema, que terá, portanto, a influência direta dos níveis superiores. Citasse como exemplo uma bacia hidrográfica, que apresenta alto, médio e baixo curso fluvial, sendo cada nível caracterizado por diferentes processos geomorfológicos presentes no domínio fluvial.

A proposta de Bertrand (1971) supera os limites do geossistema, buscando situá-lo em uma dimensão global, pois de certo modo todas as unidades de paisagem do planeta estão interligadas e influenciando umas as outras, formando um sistema global, não sendo assim possível analisá-las dissociadas do todo.

Christofoletti (1999) oberva que a analise geossistêmica é fundamental para compreender como os elementos físico-ambientais se estruturam e funcionam em sua organização espacial. Essa compreensão dará respaldo para orientar a ação humana sobre a superfície terrestre, de modo que haja uma relação harmônica entre a humanidade e a natureza.

Morelli et al. (2012) propõem o planejamento e gestão de uma bacia hidrográfica, como unidade de territorial, a partir da agregação de dados físico-naturais em um banco de dados, que serão posteriormente correlacionados aos dados referentes a ocupação humana na área, com auxilio de um Sistema de Informação Geográfica (SIG) . Este tipo de análise permite ao pesquisador avaliar de modo mais abrangente como se realiza a dinâmica entre os elementos físico-ambientais e a ação antrópica, agregando estes dois aspectos em um mesmo nível de análise.

Soares e Aquino (2012) fizeram um levantamento de diversos estudos realizados no estado do Piauí, fundamentados na teoria geossistêmica. Em tais estudos percebeu-se que a compartimentação geomorfológica constitui a base de dados primários para o estudo de áreas a partir da classificação ecodinâmica de Tricart (1977), como também para a realização de zoneamentos e macrozonamentos ambientais, fundamentados, sobretudo na concepção de Sotchava (1977); Bertrand (1971) e Rodriguez et al. (2004).

A teoria geossistêmica representa uma importante proposta metodológica para compreender a relação existente entre os elementos formadores da paisagem global. Esse conhecimento tem o poder de orientar a 
ocupação humana desses espaços, buscando estabelecer uma harmônica e passiva relação do homem e o meio.

A visão de geossistema como resultado da interação dos atributos físicos-naturais que compõe uma determinada unidade de paisagem, e que a introdução de um elemento externo a essa dinâmica, como uma ação antrópica, por exemplo, venha a gerar desajuste aos fluxos de matéria e energia, irá resultar em desequilíbrios a um sistema. Porém, percebe-se que a visão sistêmica se resume a compreender a relação que esses elementos estabelecem entre si, havendo ainda uma lacuna a ser preenchida, no que tange a compreensão do modo que se dará a nova dinâmica a partir da inserção desse novo elemento no sistema, ou até mesmo uma diferença comportamental de um de seus componentes basilares.

Hack (1960) apud Rodrigues (2001) reafirma a ideia de equilíbrio na natureza e defende a existência de ajustes recíprocos entre os sistemas e subsistemas e entre suas variáveis. Rodrigues (2001) discute a noção de dinâmica, e afirma a possibilidade de classificar o geossistema a partir do seu estado atual, ou através da ocorrência dos estados sucessivos, sendo assim possível propor de modo hipotético sua configuração futura. Desse modo, a compreensão da dinâmica da paisagem a partir de uma visão sistêmica, exige esclarecer, ou até mesmo relativizar, as nuanças comportamentais apresentadas pelos seus componentes.

A análise de áreas de risco, por exemplo, não pode ser reduzida a sobreposições de informações relativas à geologia, ao clima, ao relevo, ao solo e ao tipo de uso e ocupação da terra, pois se deve considerar, sobretudo, as variações sazonais do comportamento dos seus componentes, principalmente no que se refere a análise climática, pois este elemento frente aos aspectos geológicos-geomorfológico, dentro de uma escala de tempo humana, apresenta maior variabilidade comportamental. Outro fator também importante a ser destacado é a questão socioeconômica, pois exerce influencia direta no modo de ocupação da superfície terrestre, havendo diferentes formas de ocupação e resultados sobre o ambiente quando o uso se dá por populações de diferentes classes sociais.

O uso e ocupação da terra realizado por classes sociais de alto poder aquisitivo, na maioria das vezes, é caracterizado por apresentar boa infraestrutura e por se localizar, quase sempre, afastado de áreas que oferecem situações risco, porém, é notadamente perceptível que a infraestrutura 
Caio Lima-dos Santos, Osvaldo Girão. The Geosystemic Theory in geomorphological research:

a theoretical-conceptual approach

pública, no referente as vias de mobilidade, são majoritariamente pavimentadas, levando a um elevado índice de impermeabilização do solo que repercute na deficitária permeabilidade e hidromorfodinâmica das cidades.

No caso das populações menos favorecidas economicamente, quase sempre a ocupação do espaço ocorre de modo desordenado, sem dispor de infraestrutura básica, ocupando áreas de encosta, bordas de vertentes e fundos de vales fluviais, o que cria situações que podem gerar, ou até mesmo acentuar, processos erosivos, de movimentos de massa e alagamentos pela instalação de sistemas de saneamentos clandestinos, por exemplo, colocando essa população em situações de risco devido a sua alocação em zonas de estabilidade precária a assentamentos.

Analisar a dinâmica ambiental a partir de uma visão evolutiva se torna algo complexo e de difícil compreensão quando analisado em uma escala de tempo humana. O estudo geomorfológico, dentro de uma visão sistêmica, não pode ser pautado na simples superposição de informações físico-ambientais. Há de se considerar que variações comportamentais apresentadas por todos seus elementos sistêmicos, tanto de ordem física, quanto de ordem humana. Daí a fisionomia da paisagem resultar da interação, estando aí também registrado as ações de eventos/processos excepcionais que perturbam a dinâmica natural de um sistema. O olhar do pesquisador precisa estar sensível a estas situações, de modo que a negligencia de tais possibilidades poderá conduzir a uma analise linear e meramente descritiva.

A pesquisa geomorfológica precisa estar pautada na percepção evolutiva do relevo e de todos os elementos que o condiciona, não se restringindo apenas a sua descrição e no apontamento dos efeitos gerados pela introdução do elemento humano.

Portanto, é necessário destacar que a natureza está em constante mutação, buscando estabelecer uma nova dinâmica, mesmo que essa situação não seja compatível com escala de tempo humana, sendo assim, por vezes, difícil perceber sua dinâmica.

\section{Considerações finais}

A compreensão de geossistema apresentada propõe uma visão dinâmica e não estática da paisagem, observando todos os processos envolvidos na sua configuração atual, tendo como objetivo realizar a ocupação 
humana sobre o espaço sem que haja maiores danos a essa dinâmica e as características do ambiente físico/natural.

Levanta-se, porém os seguintes questionamentos sobre essa proposta: como é possível alcançar uma relação harmônica entre sociedade e natureza, sabendo que a evolução da paisagem natural, majoritariamente, ocorre de forma lenta e gradual a partir de processos dinâmicos, com a atuação de diversos elementos que a caracteriza, e que a ação humana, independente da intensidade, pode alterar esta dinâmica? Seria possível, portanto determinar um índice ou um grau de intensidade dessa ação, que serviria como ponto de partida para compreender se o sistema esta em equilíbrio ou evoluindo para uma situação de desequilíbrio, mesmo sabendo que a natureza apresenta inúmeros elementos que formam uma única unidade de paisagem? Como seria possível então agregar a esta variedade o legado de dados mensuráveis e não mensuráveis as características e as ações humanas?

O ponto de impasse dessa teoria está no entendimento de que a inserção de elementos humanos nessa dinâmica representa a entrada de um componente que não estava presente no sistema no momento em que se estabeleceu à dinâmica. Como será possível, portanto determinar até que ponto o sistema está em equilíbrio ou se estará evoluindo e estabelecendo uma nova dinâmica com a entrada de novos elementos? A pesquisa geossistêmica nos conduzirá realmente a uma situação de equilíbrio dinâmico, ou para um novo ponto de equilíbrio?

A pesquisa geossistêmica se mostra bastante eficiente quando nos conduz a buscar compreender a relação dinâmica que se estabelece entre os elementos que compõe um determinado geossistema. Isso favorece a ocupação organizada da superfície terrestre, pois minimiza a vulnerabilidade social frente às situações de riscos naturais. Porém, poder determinar até que ponto a alteração da dinâmica natural está condicionada a fatores humanos ainda é algo de difícil compreensão nas pesquisas cientificas de modo geral, tendo como exemplo os impasses causais relacionados à problemática de um provável aquecimento global.

Essa situação obriga a realização de uma reflexão mais aguçada dessa teoria para melhor enquadrar seus conceitos e suas propostas metodológicas, tendo em vista proporcionar o seu desenvolvimento dentro do campo da pesquisa geomorfológica. 
Caio Lima-dos Santos, Osvaldo Girão. The Geosystemic Theory in geomorphological research: a theoretical-conceptual approach

\section{Referencias}

Ab'Sáber, A. N. (1969). Um conceito de geomorfologia a serviço das pesquisas sobre o Quaternário. São Paulo, Brasil: Universidade de São Paulo, Instituto de Geografia.

Bertalanffy, L. V. (1973). Teoria Geral dos Sistemas. Petrópolis: Vozes.

Bertrand, G. (1971). Paisagem e Geografia Física global: esboço metodológico. Caderno de Ciências da Terra. São Paulo, Brasil, 27.

Bertrand, G. (2004). Paisagem e Geografia Física global: esboço metodológico. RA'E GA - O Espaço Geográfico em Análise. Curitiba, Brasil, 8, 141-152.

Christofoletti, A. (1997). Impactos no meio ambiente ocasionados pela urbanização no mundo tropical. Natureza e Sociedade Hoje. São Paulo, Brasil: Editora Hucitec, 3-97.

Christofoletti, A. (1999). Modelagem de sistemas ambientais. São Paulo, Brasil: Edgard Büchler.

Corrêa, A. C. de Barros. (2004). Unidades geoambientais do Recife. Trabalho apresentado na disciplina Metodologias de Pesquisa em Geografia Física. Recife, Departamento de Ciências Geográficas, UFPE, 7 p. (mimeogr.).

Girão, O. (2007). Análise de Processos Erosivos em Encostas na Zona Sudoeste da Cidade do Recife - Pernambuco. Tese de doutorado. Universidade Federal do Rio de Janeiro, CCMN. Brasil. (pp.305)

Hack, J. T. (1960). Interpretation of erosional topography in humid temperate regions. American Journal of Science, 258, 80-97.

Marques, R. (2008). A abordagem sistêmica e os estudos geomorfológicos: algumas interpretações e possibilidades de aplicação. Revista Geografia (Londrina), 17(2), 67-87.

Mendonça, F. (1989). Geografia fisica: Ciência humana? São Paulo, Brasil: Contexto.

Monteiro, C. A. F. (1978). Derivações Antropogênicas dos Geossistemas Terrestres no Brasil e Alterações Climáticas: perspectivas urbanas e agrárias ao problema da elaboração de modelos de avaliação. Simpósio da Comunidade Vegetal como Unidade Biológica, Turística e Econômica, 1(15), 43-76.

Monteiro, C. A. F. (2000). Geossistemas: A história de uma procura. São Paulo, Brasil: Contexto. 
Morelli, S., Segoni, S., Manzo, G., Ermini, L. y Catani, F. (2012). Urban planning, flood risk and public policy: The case of the Arno River, Firenze, Italy. Applied Geography, 1(34), 205-218.

Rodrigues, C. (2001). A teoria geossistêmica e sua contribuição aos estudos geográficos e ambientais. Revista do Departamento de Geografia, 14(1), 69-77.

Rodriguez, J. M. M.; Silva, E. V.; Cavalcanti, A. P. B. (2004) Geoecologia das Paisagens: uma visão geossistêmica da análise ambiental. Fortaleza: Editora UFC.

Silva, M. L. (2008). Paisagem e geossistema: contexto histórico e abordagem teórico-metológica. Revista Geoambiente on-line, 3(5), 1-23.

Soares, J. P. R. y Aquino, C. M. S. (2012). Análise sistêmica: contribuição teórico metodológica e aplicações no Estado do Piuí. ACTA geográfica, 6, (13), 239-255.

Sotchava, V. B. (1977). O estudo dos geossistemas. Métodos em questão. São Paulo, Brasil.

Tricart, J. (1977). Ecodinâmica. Rio de Janeiro, Brasil: SUPREN. 